\title{
TP53 mutations determined by targeted NGS in breast cancer: a case-control study
}

\author{
Angeliki Andrikopoulou ${ }^{1}$, Evangelos Terpos ${ }^{1}$, Spyridoula Chatzinikolaou ${ }^{1}$, Kleoniki \\ Apostolidou ${ }^{1}$, Ioannis Ntanasis-Stathopoulos ${ }^{1}$, Maria Gavriatopoulou ${ }^{1}$, Meletios- \\ Athanasios Dimopoulos ${ }^{1}$ and Flora Zagouri $^{1}$ \\ ${ }^{1}$ Department of Clinical Therapeutics, Alexandra Hospital Medical School, Athens 11528, Greece \\ Correspondence to: Flora Zagouri, email: florazagouri@yahoo.co.uk \\ Keywords: TP53 mutations; next-generation sequencing; biomarker; prognosis; breast cancer \\ Received: July 15, $2021 \quad$ Accepted: August 28, $2021 \quad$ Published: October 12, 2021
}

Copyright: (๑ 2021 Andrikopoulou et al. This is an open access article distributed under the terms of the Creative Commons Attribution License (CC BY 3.0), which permits unrestricted use, distribution, and reproduction in any medium, provided the original author and source are credited.

\section{ABSTRACT}

Background: Tumor protein 53 (TP53) gene mutations are identified in up to $37 \%$ of breast tumors especially in HER-2 positive and basal-like subtype. Previous studies have indicated TP53 mutations as a prognostic biomarker in breast cancer. However, most of these studies performed immunohistochemistry (IHC) for the detection of TP53 mutations.

Aim: The purpose of our study is to evaluate the role of TP53 somatic mutations detected via next-generation sequencing (NGS) as a potential prognostic marker in patients with breast cancer.

Materials and Methods: 82 female patients with Stage I-III breast cancer underwent NGS in paraffin blocks and blood samples during the period 25/09/2019 through 25/05/2021. 23 cases of somatic TP53 mutations and 23 cases of healthy controls were matched on age at diagnosis, menopausal status, histological subtype, histological grade, ki67 expression and disease stage.

Results: Mean age at diagnosis was 52.35 (SD; 11.47) years. The somatic TP53 mutation NM_000546.5:C.824G >A p.(Cys275Tyr) was most frequently detected. Co-existence of PIK3CA mutation was a common finding in somatic TP53-mutant tumors $(4 / 23 ; 17.4 \%)$. Disease-free survival was shorter in TP53-mutated cases (16.3 months vs. 62.9 months). TP53 pathogenic somatic mutations were associated with a 8-fold risk of recurrence in the univariate Cox regression analysis $(O R=8.530$, 95\% CI: 1.81-40.117; $p=0.007$ ).

Conclusions: Our case-control study suggests that TP53 somatic mutations detected by next-generation sequencing (NGS) are associated with an adverse prognosis in breast cancer.

\section{INTRODUCTION}

TP53 gene is the most frequently mutated gene $(>50 \%)$ in human cancer, indicating its crucial role as a tumor suppressor [1]. TP53 gene encodes $\mathrm{p} 53$ protein which is considered as "the guardian of the genome" by binding to specific DNA sequences and maintaining genomic stability [2]. P53 protein is involved in cell response to stress signals, activates DNA repair proteins and regulates the production of stem cells [3]. The fundamental role of TP53 is evident in Li-Fraumeni syndrome which is characterized by germline mutations of TP53 and predisposition to aggressive tumors like earlyonset breast cancer (25\%), soft-tissue or bone sarcomas $(35 \%)$ and brain tumors. In breast cancer, germline TP53 mutations harbor $5-8 \%$ of cases of early-onset (under 30 years old) disease, while up to $85 \%$ of women who carry germline TP53 mutations eventually develop breast 
cancer [4]. On the other hand, somatic TP53 mutations are identified in $37 \%$ of all breast cancers and is more frequently mutated in HER-2 positive (72\%) and basallike subtype (80\%) [5]. DNA sequencing is considered as the gold-standard for the detection of TP53 mutations that usually harbor the exons 5-8 of the gene [6]. More recently, next generation sequencing has allowed the detection of TP53 mutations outside this restricted region.

There are numerous studies assessing the clinical significance of TP53 mutations in breast cancer. However, the results of these studies are often contradicting. TP53 mutation was associated with worse prognosis in breast cancer patients regardless of the tumor subtype and the type of treatment administered. Initially, p53 IHC expression was associated with an adverse prognosis in small retrospective studies [7-9]. More recent studies evaluated TP53 gene mutations in breast cancer via DNA sequencing [10-13]. P53 mutation was associated with negative estrogen and progesterone receptor (ER/ PR) status and increased mortality rate in 859 breast cancer women [10]. TP53 mutations within exons 5 to 8 detected by gene sequencing were related to increased risk of breast cancer-specific death regardless of tumor size, nodal status and hormone receptor expression [11]. Moreover, P53 mutation status has been associated with response to breast cancer treatment. A METABRIC analysis of breast cancer patients that received only endocrine treatment linked TP53 mutations to worse survival [6], while a meta-analysis of 3,476 cases of patients receiving neoadjuvant treatment concluded that TP53 mutation status is a predictor of response to neoadjuvant chemotherapy [14].

The aim of this study is to evaluate the role of somatic TP53 mutations as a potential prognostic marker in Stage I-III breast cancer patients treated in a single center via a case-control study. The identification of TP53 mutations was performed via next-generation sequencing (NGS) in paraffin blocks of the patients enrolled.

\section{RESULTS}

\section{Clinicopathological characteristics}

Patient characteristics (age, date at diagnosis, menopausal status), histopathological parameters (histological type, grade, ER/PR expression, HER2 expression, ki67, stage) and treatment administered (surgery, chemotherapy, anti-HER2 treatment, hormonotherapy) in cases and controls are summarized in Tables 1 and 2 .

Mean age at diagnosis was 52.35 (SD; 11.47) years in cases and 49.26 years $(\mathrm{SD} ; 11.27)$ years in controls $(p=0.362)$. Overall, there were not statistically significant differences between cases and controls in terms of age at diagnosis $(p=0.362)$, menopausal status $(p=0.492)$, stage at diagnosis $(p=0.802)$, histology $(p=$
$0.368)$, hormone status $(p=0.760)$, HER2 expression $(p=0.760)$, grade (G1 vs. G2/3; $p=0.506)$ and Ki67 status $(p=0.681)$. Patients with stage I-III disease $(23 ; 100 \%)$ underwent surgical excision $(20 ; 87 \%)$ and adjuvant radiation $(17 ; 73.9 \%)$. Invasive ductal carcinoma (IDC) was diagnosed in most of the cases (22; $95.7 \%)$. The majority of cases were hormone receptorpositive $(14 ; 60.9 \%)$, HER2-negative $(14 ; 60.9 \%)$ and characterized by low differentiation $(17 ; 73.9 \%)$ and high Ki67 expression (20; 87\%).

\section{Genetic polymorphisms of TP53 somatic mutations}

Genetic polymorphisms of TP53 pathogenic somatic mutations identified are summarized in Table 3. Of note, the most frequent pathogenic somatic TP53 mutations reported in our patients were $c .824 G>A$ p.Cys 275 Tyr $(n=3)$ and $c .743 G>A$ p.Arg248Gln $(n=2)$ while the other polymorphisms were detected only once.

We examined the presence of other pathogenic mutations along with TP53 mutations. The genomic profile of our cases is summarized in Table 4. Of note, PIK3CA was the most frequent pathogenic mutation detected in somatic TP53-mutant tumors $(4 / 23 ; 17.4 \%)$. Other pathogenic mutations identified included AKT1, PTEN and NRAS mutations. Of note, a number of mutations of unknown significance were frequently reported. The most common mutations of unknown significance (VUS) identified were: ROS1 (10/23), KMT2C (6/23), NF1 (4/23), RET (2/23), NOTCH1 (2/23).

\section{Survival analysis}

Disease-free survival (DFS) was evaluated in cases and controls. DFS was 16.3 months in cases harboring TP53 somatic mutations (95\% CI; $11.38-21.25)$ versus 62.9 months in TP53 wild-type controls (95\% CI; 40.8-85). Somatic TP53 mutations were associated with shorter DFS in our study. Figure 1 presents Kaplan Meier DFS curves for cases and controls. TP53 mutation was associated with a 8 -fold risk of recurrence in the Cox regression analysis $(\mathrm{OR}=8.530,95 \% \mathrm{CI}$ : $1.81-40.117$; $p=0.007)$.

\section{DISCUSSION}

We here demonstrate that pathogenic somatic TP53 mutations are associated with a decreased diseasefree survival in patients with early-stage breast cancer. We retrospectively identified 23 breast cancer patients harboring TP53 somatic mutations identified via nextgeneration sequencing and 23 TP53 wild-type controls matched on age and clinicopathological characteristics. DFS was significantly reduced in TP53-mutated cases (16 vs. 63 months). 
Table 1: Clinicopathological characteristics of cases and controls

\begin{tabular}{|c|c|c|c|}
\hline $\begin{array}{l}\text { Variable } \\
\text { Continuous variables }\end{array}$ & $\begin{array}{c}\text { Cases } \\
\text { Mean (SD) }\end{array}$ & $\begin{array}{l}\text { Controls } \\
\text { Mean (SD) }\end{array}$ & $p$-value \\
\hline Age at diagnosis & $52.35(11.47)$ & $49.26(11.27)$ & $p=0.362$ \\
\hline Menopausal status & & & $p=0.492$ \\
\hline Premenopausal & $8(34.8 \%)$ & $12(52.2 \%)$ & \\
\hline Perimenopausal & $4(17.4 \%)$ & $3(13.0 \%)$ & \\
\hline Postmenopausal & $11(47.8 \%)$ & $8(34.8 \%)$ & \\
\hline Surgery & & & $p=0.295$ \\
\hline Yes & $20(87.0 \%)$ & $22(95.7 \%)$ & \\
\hline No & $3(13.0 \%)$ & $1(4.3 \%)$ & \\
\hline Stage at diagnosis & & & $p=0.802$ \\
\hline$I$ & $5(21.7 \%)$ & $4(17.4 \%)$ & \\
\hline II & $6(26.1 \%)$ & $8(34.8 \%)$ & \\
\hline III & $12(52.2 \%)$ & $11(14.8 \%)$ & \\
\hline Breast tumor location & & & $p=0.546$ \\
\hline Left & $13(56.5 \%)$ & $15(65.2 \%)$ & \\
\hline Right & $10(43.5 \%)$ & $8(34.8 \%)$ & \\
\hline Histology & & & $p=0.368$ \\
\hline$I D C$ & $22(95.7 \%)$ & $22(95.7 \%)$ & \\
\hline$I L C$ & $1(4.3 \%)$ & $0(0 \%)$ & \\
\hline Other & $0(0.0 \%)$ & $1(4.3 \%)$ & \\
\hline Hormone status & & & $p=0.760$ \\
\hline Positive & $14(60.9 \%)$ & $15(65.2 \%)$ & \\
\hline Negative & $9(39.1 \%)$ & $8(34.8 \%)$ & \\
\hline ER status & & & $p=0.546$ \\
\hline Positive & $10(43.5 \%)$ & $8(34.8 \%)$ & \\
\hline Negative & $13(56.5 \%)$ & $15(65.2 \%)$ & \\
\hline PR status & & & $p=0.552$ \\
\hline Positive & $12(52.2 \%)$ & $14(60.9 \%)$ & \\
\hline Negative & $11(47.8 \%)$ & $9(39.1 \%)$ & \\
\hline HER2 status & & & $p=0.760$ \\
\hline Positive & $9(39.1 \%)$ & $8(34.8 \%)$ & \\
\hline Negative & $14(60.9 \%)$ & $15(65.2 \%)$ & \\
\hline \multicolumn{4}{|l|}{ Grade } \\
\hline G1 & $1(4.3 \%)$ & $0(0.0 \%)$ & $p=0.506$ \\
\hline$G 2$ & $5(21.7 \%)$ & $7(30.4 \%)$ & \\
\hline G3 & $17(73.9 \%)$ & $16(69.6 \%)$ & \\
\hline Ki67 & & & $p=0.681$ \\
\hline$<20 \%$ & $3(13.0 \%)$ & $4(17.4 \%)$ & \\
\hline$\geq 20 \%$ & $20(87.0 \%)$ & $19(82.6 \%)$ & \\
\hline
\end{tabular}

In our study TP53 somatic mutations were associated with high grade $(\mathrm{G} 2 / 3: 22 ; 95.7 \%)$ and high proliferating (Ki67 > 20\%: 87\%) breast tumors. This is in accordance with previous results that TP53 mutations are more frequently identified in HER2- positive and triple negative breast tumors (TNBC), while the incidence is low in luminal A tumors. TP53 mutation is indicative of a more aggressive entity and affects tumor response to treatment [15]. P53 regulates epithelial to mesenchymal (EMT) process and stem cell 
Table 2: Type of treatment administered in cases and controls

\begin{tabular}{|c|c|c|c|}
\hline Adjuvant chemotherapy & & & $p=0.636$ \\
\hline No & $3(13.0 \%)$ & $2(8.7 \%)$ & \\
\hline Yes & $20(87.0 \%)$ & $21(91.3 \%)$ & \\
\hline Adjuvant radiation & & & $p=0.743$ \\
\hline No & $6(26.1 \%)$ & $7(30.4 \%)$ & \\
\hline Yes & $17(73.9 \%)$ & $16(69.6 \%)$ & \\
\hline Anti-Her 2 treatment & & & $p=0.760$ \\
\hline No & $14(60.9 \%)$ & $15(65.2 \%)$ & \\
\hline Yes & $9(39.1 \%)$ & $8(34.8 \%)$ & \\
\hline \multicolumn{4}{|l|}{ Disease progression } \\
\hline No & $14(60.9 \%)$ & $21(91.3 \%)$ & \\
\hline Yes & $9(39.1 \%)$ & $2(8.7 \%)$ & \\
\hline
\end{tabular}

Table 3: Genetic polymorphisms of pathogenic somatic TP53 mutations

\begin{tabular}{lclcc}
\hline TP53 genetic polymorphism & NCBI genomes browser & Type & Clinical significance & Frequency \\
\hline c.614A $>$ G p.Tyr205Cys & Rs1057520007 & Somatic & Pathogenic & 1 \\
c.559+1G $>$ A & Rs1131691042 & Somatic & Pathogenic & 1 \\
c.824G $>$ A p.Cys275Tyr & Rs863224451 & Somatic & Pathogenic & 3 \\
c.488A $>$ G p.Tyr163Cys & Rs148924904 & Somatic & Pathogenic & 1 \\
c.818G $>$ T p.Arg273Leu & Rs28934576 & Somatic & Pathogenic & 1 \\
c.714_715insT p.Asn239Ter & Rs1567549651 & Somatic & Pathogenic & 1 \\
c.536A $>$ G p.His179Arg & Rs1057519991 & Somatic & Pathogenic & 1 \\
c.85_86del p.Asn29GlnfsTer13 & Rs1555526931 & Somatic & Pathogenic & 1 \\
c.586C $>$ T p.Arg196* & Rs397516435 & Somatic & Pathogenic & 1 \\
c.797G $>$ A p.Gly266Glu & Rs193920774 & Somatic & Pathogenic & 1 \\
c.853G $>$ A p.Glu285Lys & Rs112431538 & Somatic & Pathogenic & 1 \\
c.990del p.Gln331Argfs*14 & Rs11575996 & Somatic & Pathogenic & 1 \\
c.742C $>$ T p.Arg248Trp & Rs121912651 & Somatic & Pathogenic & 1 \\
c.722C $>$ T p.Ser241Phe & Rs28934573 & Somatic & Pathogenic & 1 \\
c.743G $>$ A p.Arg248Gln & Rs11540652 & Somatic & Pathogenic & 2 \\
c.638G $>$ T p.Arg213Leu & Rs587778720 & Somatic & Pathogenic & 1 \\
c.455C $>$ T p.Pro152Leu & Rs587782705 & Somatic & Pathogenic & 1 \\
c.817C $>$ T p.Arg273Cys & Rs121913343 & Somatic & Pathogenic & 1 \\
c.681_682insT p.Asp228Ter & Rs1567550002 & Somatic & Pathogenic & 1 \\
c.626_627del p.Arg209LysfsTer6 & Rs1057517840 & Somatic & Pathogenic & 1 \\
\hline
\end{tabular}

characteristics through upregulation of miR200c [15]. Mutant TP53 tumors suppress transcriptional factors involved in the TGF- $\beta$ signaling pathway (e.g. ZEB2/ SIP1, Snail, Twist) and induce epithelial-mesenchymal transition (EMT). Moreover, genes involved in cell migration like the matrix metalloproteinase family member MMP1 were overexpressed in TP53 mutated tumors [15]. Overall, TP53 mutational status was related 
Table 4: Somatic/germline mutations identified in TP53-mutated cases

\begin{tabular}{|c|c|c|c|c|}
\hline Cases & TP53 somatic mutation & $\begin{array}{l}\text { TP53 germline } \\
\text { mutations }\end{array}$ & $\begin{array}{c}\text { Co-existing pathogenic } \\
\text { mutations }\end{array}$ & Co-existing VUS mutations \\
\hline 1 & c. $614 \mathrm{~A}>$ G p. Tyr205Cys & - & - & - \\
\hline 2 & c. $559+1 \mathrm{G}>\mathrm{A}$ & - & PIK3CA (Glu545Lys) & - \\
\hline 3 & c. $824 \mathrm{G}>$ A p.Cys 275 Tyr & - & - & $\begin{array}{l}\text { KMT2C (Arg2609Gln), } \\
\text { RB1 (Asn663Ser), NOTCH1 (Leu818Pro) }\end{array}$ \\
\hline 4 & c. $488 \mathrm{~A}>$ G p.Tyr163Cys & - & - & $\begin{array}{l}\text { RAD50 (Arg365Gln), } \\
\text { TP53 (Leu188Lysfs*59), CCND1 } \\
(\text { c. } 724-2 \mathrm{~A}>\text { C) }\end{array}$ \\
\hline 5 & c. $824 \mathrm{G}>$ A p.Cys $275 \mathrm{Tyr}$ & - & AKT1 (Glu17Lys) & - \\
\hline 6 & c. $818 \mathrm{G}>$ T p.Arg273Leu & - & PIK3CA (Glu39Lys) & - \\
\hline 7 & c.714_715insT p.Asn239Ter & - & - & $\begin{array}{l}\text { ROS1 } \\
\text { (Gly2245Ser) } \\
\text { ROS1 } \\
\text { (Thr145Pro) }\end{array}$ \\
\hline 8 & c. $536 \mathrm{~A}>\mathrm{G}$ p.His179Arg & $\begin{array}{l}\text { c. } 847 \mathrm{C}>\mathrm{T} \\
\text { p.Arg283Cys }\end{array}$ & - & $\begin{array}{l}\text { Somatic: } \\
\text { ROS1 (Thr2195Ser) } \\
\text { TP53 } \\
\text { (Arg283Cys) } \\
\text { Germline: PMS2 (His189Pro) }\end{array}$ \\
\hline 9 & c.85_86del: p.Asn29GlnfsTer13 & - & - & $\begin{array}{l}\text { ROS1 (Thr145Pro) } \\
\text { BRCA2 (Phe3289Leu) }\end{array}$ \\
\hline 10 & c. $586 \mathrm{C}>\mathrm{T}$ p. $\operatorname{Arg} 196^{*}$ & - & - & - \\
\hline 11 & c. $797 \mathrm{G}>$ A p.Gly266Glu & - & $\begin{array}{l}\text { PIK3CA (Glu545Lys), } \\
\text { PTEN (Glu285Glyfs*13) }\end{array}$ & MSH2 (Glu561Lys), NOTCH1 (Glu606Lys) \\
\hline 12 & c. $824 \mathrm{G}>$ A p.Cys $275 \mathrm{Tyr}$ & - & - & ROS1 (Thr145Pro), RET (Thr562Ser) \\
\hline 13 & c. $853 \mathrm{G}>$ A p.Glu285Lys & - & - & ROS1 (Thr145Pro), NF1 (Met102Val) \\
\hline 14 & c.990del p.Gln331Argfs*14 & - & - & MET (Pro1364Ser), NF1 (Ala188Glu) \\
\hline 15 & c. $742 \mathrm{C}>\mathrm{T}$ p.Arg248Trp & - & - & $\begin{array}{l}\text { ROS1 (Arg167Gln), NF1 (Asp2465Glu), } \\
\text { ERBB2 (Arg487Gln), AR (Glu494Ala) }\end{array}$ \\
\hline 16 & c. $722 \mathrm{C}>\mathrm{T}$ p.Ser $241 \mathrm{Phe}$ & - & $\begin{array}{l}\text { PIK3CA (Glu545Lys), } \\
\text { NRAS (Gly60Arg) }\end{array}$ & $\begin{array}{l}\text { BRCA2 (Arg1160Gly), BRCA2 } \\
\text { (Cys1159Tyr), CDKN2A (Arg10Trp), RET } \\
\text { (Glu768Lys), STK11(Val66Met), STK11 } \\
\text { (Gly408Ser), NF1 (Ala2485Gly) }\end{array}$ \\
\hline 17 & c. $743 \mathrm{G}>$ A p. $\operatorname{Arg} 248 \mathrm{Gln}$ & - & - & KMT2C (Glu1625Lys) \\
\hline 18 & c. $638 \mathrm{G}>\mathrm{T}$ p.Arg213Leu & - & - & $\begin{array}{l}\text { KDR (Leu625Phe), CDK4 (Glu265Lys), } \\
\text { CDK4 (Met264Ile) }\end{array}$ \\
\hline 19 & c. $817 \mathrm{C}>\mathrm{T}$ pArg273Cys & - & - & $\begin{array}{l}\text { ROS1 (Arg1942Trp) } \\
\text { KMT2C (Gly4411Arg) }\end{array}$ \\
\hline 20 & c. $455 \mathrm{C}>\mathrm{T}$ p.Pro152Leu & - & - & $\begin{array}{l}\text { ROS1 (Thr145Pro), MET (Pro1382Ser), } \\
\text { KMT2C (Asp2692Ala) } \\
\text { MYC (Asn26Ser) }\end{array}$ \\
\hline 21 & c. $743 \mathrm{G}>$ A: p.Arg248Gln & - & - & $\begin{array}{l}\text { ROS1 } \\
(\text { Arg167Gln) } \\
\text { KMT2C (Arg1292Gln) }\end{array}$ \\
\hline 22 & c.681_682insT p.Asp228Ter & - & - & $\begin{array}{l}\text { MTOR (Arg1896Gln) } \\
\text { ROS1 (Gly2245Ser) } \\
\text { KMT2C (Ile439Val) }\end{array}$ \\
\hline 23 & c.626_627del: p.Arg209LysfsTer6 & - & - & $\begin{array}{l}\text { PIK3CA (Gly439Ala) } \\
\text { CDK6 (Arg90Thr) } \\
\text { JAK2 (Glu1024Lys) }\end{array}$ \\
\hline
\end{tabular}

to reduced cell differentiation and increased metastatic ability.

An interesting finding of our study was the coexistence of TP53 mutations with pathogenic somatic
PIK3CA mutations in the $17.4 \%$ of the cases. PIK3CA mutations are detected in more than one third of HR-positive breast tumors (34.5\%) and less frequently in HER2-overexpressing tumors $(22.7 \%)$, whereas the 
incidence drops to $8.3 \%$ in triple-negative and basallike breast cancer [16]. It has been previously shown that co-mutation of TP53 and PIK3CA account for more than $6 \%$ of breast cancers and for approximately $30 \%$ of TP53-mutated tumors [17]. Co-mutated tumors represent an aggressive entity and were associated with a worse progression-free survival [17]. In our study, co-existence of these mutations was not a rare event. The effect of the simultaneous presence of TP53 and PIK3CA mutations on response to chemotherapy and prognosis needs to be further addressed.

Our case-control study demonstrated that TP53 pathogenic somatic mutations are associated with a reduced disease-free survival in early-stage breast cancer. In agreement with our findings, previous studies report an adverse prognosis in patients harboring TP53 mutations [6]. Some other studies suggest that TP53 mutations have a distinct role in different breast cancer subtypes. TP53 somatic mutations were associated with a worse prognosis in patients with luminal B and HER2positive breast tumors, but not in patients with luminal A and basal-like tumors [18]. Moreover, TP53 mutations are linked to different response rates to different treatment regimens. One study suggests that TP53 wildtype tumors respond better to hormone therapy, while the opposite effect is identified in patients that receive chemotherapy only [19]. TP53 status may have a distinct clinical role according to the tumor subtype and the type of treatment administered.
One strength of our study was the detection method applied for the identification of TP53 mutations. DNA sequencing is currently the gold standard for identification of TP53 mutations [20]. Recently, next generation sequencing has emerged as a highly accurate alternative since it offers the ability of detecting mutations outside exons 5-8. Accuracy of immunohistochemistry (IHC) is limited by the presence of null mutations (nonsense mutations, deletions, insertions etc) in TP53 gene that result in a detectable but unstable protein. In these cases that account for up to $\sim 40 \%$ of TP53 mutations in breast cancer IHC will fail to detect TP53 mutation. Consequently, IHC detection of TP53 status should be evaluated with caution. Our study overcomes this limitation by applying next generation sequencing in patient samples further increasing the validity of the data presented. Despite the originality, limitations of this case-control study should be acknowledged. Our study is confined to a single institution and thus the sample size is limited. More studies with a larger sample size should be performed to confirm our results. A multicenter study with a similar design could generate more robust scientific data.

We here show that TP53 pathogenic somatic mutations are associated with a shorter DFS in early-stage breast cancer patients. In addition, TP53 mutations often coexist with PIK3CA mutations in breast tumors (17.4\%). Future well designed studies should be performed to address the clinical role of the co-existence of these mutations in breast cancer.

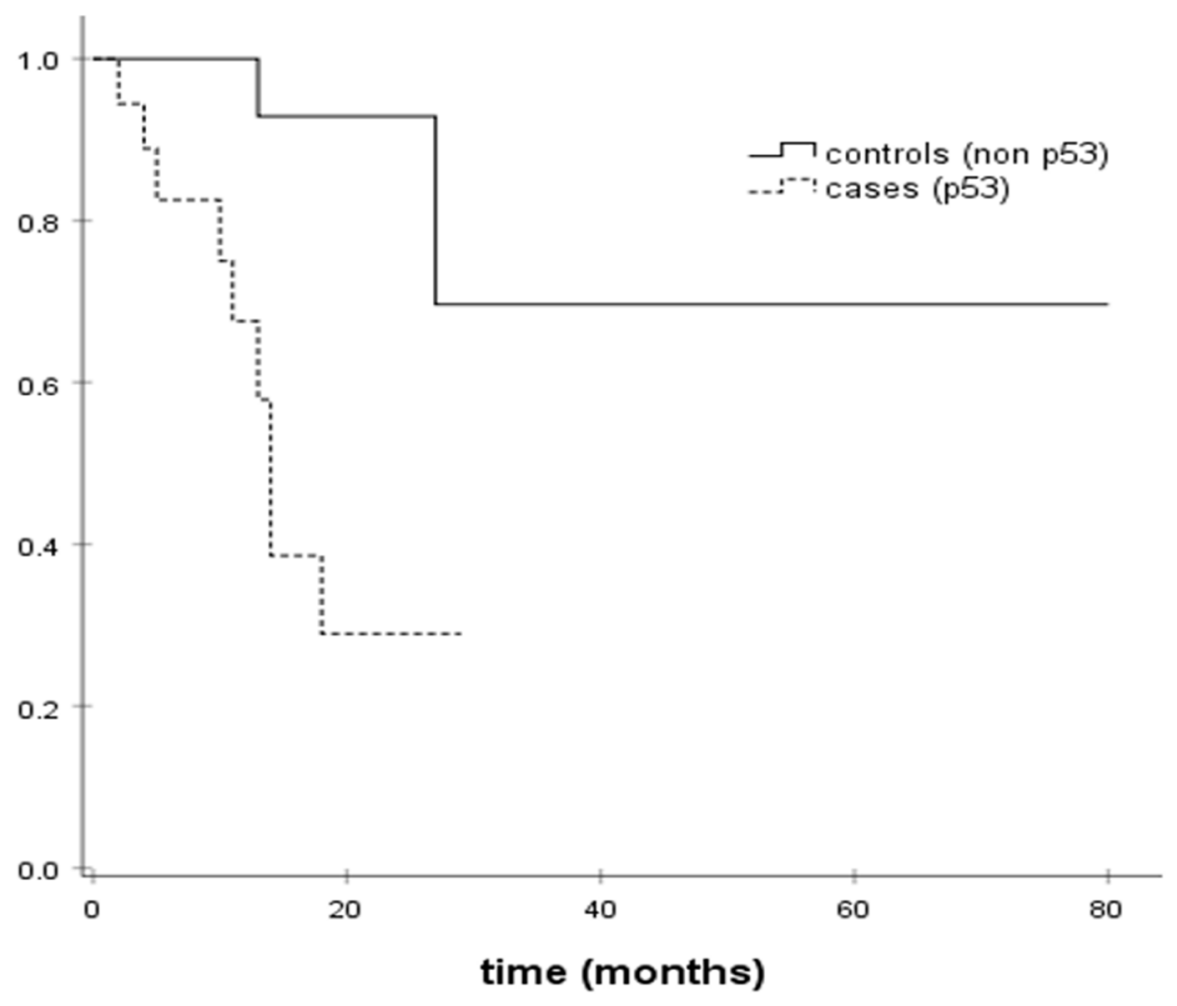

Figure 1: Kaplan-Meier DFS estimates. 


\section{MATERIALS AND METHODS}

\section{Subjects}

Incident cases of 82 patients with histologically confirmed Stage I-III breast cancer that underwent NGS in paraffin blocks and blood samples during the period $25 / 09 / 2019$ to $25 / 05 / 2021$ were retrospectively collected. Among them 23 cases of somatic TP53 mutations were detected and were matched on age at diagnosis ( \pm 5 years), histological subtype (luminal A, luminal B, HER2-enriched, TNBC), histological grade (1 vs. 2/3), menopausal status, ki67 expression and disease stage as classified by TNM classification system with controls; controls included 23 women with TP53 wildtype breast cancer. All women were treated in a single Institute at the Oncology Department of "Alexandra" Hospital, Medical School, University of Athens, Greece. Immunohistochemical (IHC) analysis was performed to quantify expression of human epidermal growth factor receptor 2 (HER2), hormone receptors (HR) and Ki67. Estrogen receptor (ER) and progesterone receptor $(\mathrm{PR})$ were considered positive if tumors had more than $1 \%$ nuclear-stained cells. HER2 status was considered positive when graded as $3+$, while 0 to $1+$ were negative and 2+ was an inconclusive result and in situ hybridization (ISH) was performed in those cases to confirm positivity. Hormone receptor positive tumors characterized by ki67 expression of over $20 \%$ were considered as luminal B. Information on histological characteristics (tumor subtype, grade, ER/PR expression, HER2 expression, expression levels of ki67), TNM stage (tumor size, lymph node infiltration, metastasis), type of surgery performed, type of chemotherapy administered, disease-free survival and overall survival were collected from patient files and were registered on an electronic database. Both cases and controls were Caucasian and reside in the same geographical region. This case-control study is in accordance with the Helsinki Declaration and has been approved by the Review Board of Alexandra General Hospital of Athens. An informed consent form was obtained from each of the eligible patients.

\section{DNA extraction}

For breast cancer patients, paraffin-embedded breast tissues derived from mastectomy or breast conserving operation before adjuvant treatment and blood samples were analyzed. Paraffin-embedded breast tissues were cut at slices of $10 \mu \mathrm{m}$ diameter. Tumor DNA was isolated from paraffin-embedded breast tissues using the QIAamp DNA FFPE Tissue or the kit Ion Ampliseq Custom Next Generation Sequencing (NGS) DNA panel (Amplicon Sequencing following the manufacturer's instructions. Plasma blood samples were collected in Vacutainer tubes.
Within 4 hours after collection, plasma was separated from whole blood samples through centrifugation for $10 \mathrm{~min}$ at $3000 \mathrm{rpm}$ at room temperature and stored at $-80^{\circ} \mathrm{C}$ until further use. Isolation of plasma DNA was performed using QIAsymphony DSP DNA Mini Kit and the genomic library was constructed using Trusight ${ }^{\mathrm{TM}}$ Comprehensive Hereditary Cancer Panel - Nextera ${ }^{\mathrm{TM}}$ DNA Flex Preenrichment Library Prep according to the manufacturer's instructions.

\section{Targeted sequencing}

The NGS study on paraffin-embedded breast tissues was performed using Ion Torrent platform (Ion S5Prime) with a median amplicon cover 2000x (whenever DNA extraction was performed with kit Ion Ampliseq). For the data annotation and analysis IonReporter (v5.12) (Thermo Scientific) was used. The sequences were aligned to the human genome reference sequence GRCh37-hg19. An additional manual data curation was performed using data from OncomineReporter (v4.4) and relevant databases (CinVar, dbSNP, Ensemble, COSMIC, CIVIC, PharmGKB, OMIM, My Cancer Genome, Vasome etc.). For the tissues that underwent DNA extraction via the QIAamp DNA FFPE Tissue, libraries were constructed using AmpliSeq for Illumina Comprehensive Panel v3. The NGS study was performed using the Illumina platform (MiSeq, NextSeq500 or NovaSeq) in these cases with a median amplicon cover 500x for the $88.8 \%$ of the targeted regions.

\section{Plasma DNA sequencing}

Genomic libraries were constructed using Trusight ${ }^{\mathrm{TM}}$ Comprehensive Hereditary Cancer Panel - Nextera $^{\mathrm{TM}}$ DNA Flex Pre-enrichment Library Prep according to the manufacturer's instructions. Plasma sequencing was performed using Illumina platform (NextSeq500/ NovaSeq). The validation of results was performed according to criteria of American College of medical Genetics - ACMG [21] and NCCN guidelines.

\section{Statistical analysis}

The statistical analysis was performed with SPSS 24.0 statistical software. Differences between cases and controls were examined by Student's $t$-test for continuous variables or the chi-square test for categorical variables. Pearson's correlation and Fisher's exact test (for categorical variables) were used. The threshold for statistical significance was set at $p<0.05$. Univariate Cox regression analysis was performed to evaluate the association of TP53 mutation with diseasefree survival in breast cancer patients. Kaplan-Meier survival curves were estimated to graphically represent the results. 


\section{Abbreviations}

TP53: Tumor protein 53; NGS: next-generation sequencing; PIK3CA: phosphatidylinositol-4,5bisphosphate 3-kinase, catalytic subunit alpha; DFS: disease-free survival; ER: estrogen receptor; PR: progesterone receptor; HER2: human epidermal growth factor receptor 2; IHC: immunohistochemistry; IDC: invasive ductal carcinoma; VUS: variants of unknown significance; TNBC: triple negative breast cancer; EMT: epithelial to mesenchymal transition; FFPE: Formalinfixed paraffin-embedded.

\section{Author contributions}

Project administration and supervision: Evangelos Terpos, Meletios-Athanasios Dimopoulos and Flora Zagouri; Data curation: Angeliki Andrikopoulou, Spyridoula Chatzinikolaou, Ioannis NtanasisStathopoulos; Formal analysis: Kleoniki Apostolidou; Investigation: Angeliki Andrikopoulou, Spyridoula Chatzinikolaou, Ioannis Ntanasis-Stathopoulos, Visualization: Flora Zagouri, Writing - original draft: Angeliki Andrikopoulou, Spyridoula Chatzinikolaou, Ioannis Ntanasis-Stathopoulos, Writing - review \& editing, Angeliki Andrikopoulou, Maria Gavriatopoulou. All the authors have read and approved the final manuscript. All authors agreed with the content and all gave explicit consent to submit and all obtained consent from the responsible authorities at the institute where the study was carried out. FZ is the corresponding author and guarantor of the review.

\section{CONFLICTS OF INTEREST}

M.L. has received honoraria from Roche, Astra Zeneca, Astellas, MSD, Janssen, Bristol-Myers-Squibb and IPSEN. M.-A.D. has received honoraria from participation in advisory boards from Amgen, BristolMyers-Squibb, Celgene, Janssen, Takeda. F.Z. has received honoraria for lectures and has served in an advisory role for Astra-Zeneca, Daiichi, Eli-Lilly, Merck, Novartis, Pfizer, and Roche. The remaining authors declare no conflicts of interest.

\section{FUNDING}

This research did not receive any specific grant from funding agencies in the public, commercial, or not-forprofit sectors.

\section{REFERENCES}

1. Surget S, Khoury MP, Bourdon JC. Uncovering the role of p53 splice variants in human malignancy: a clinical perspective. Onco Targets Ther. 2013; 7:57-68. https://doi. org/10.2147/OTT.S53876. [PubMed]

2. Lane DP. Cancer. p53, guardian of the genome. Nature. 1992; 358:15-16. https://doi.org/10.1038/358015a0. [PubMed]

3. Lane D, Levine A. p53 Research: the past thirty years and the next thirty years. Cold Spring Harb Perspect Biol. 2010; 2:a000893. https://doi.org/10.1101/cshperspect.a000893. [PubMed]

4. Schon K, Tischkowitz M. Clinical implications of germline mutations in breast cancer: TP53. Breast Cancer Res Treat. 2018; 167:417-23. https://doi.org/10.1007/s10549-0174531-y. [PubMed]

5. Cancer Genome Atlas Network. Comprehensive molecular portraits of human breast tumours. Nature. 2012; 490:6170. https://doi.org/10.1038/nature11412. [PubMed]

6. Shahbandi A, Nguyen HD, Jackson JG. TP53 Mutations and Outcomes in Breast Cancer: Reading beyond the Headlines. Trends Cancer. 2020; 6:98-110. https://doi.org/10.1016/j. trecan.2020.01.007. [PubMed]

7. Yamashita H, Toyama T, Nishio M, Ando Y, Hamaguchi M, Zhang Z, Kobayashi S, Fujii Y, Iwase H. p53 protein accumulation predicts resistance to endocrine therapy and decreased post-relapse survival in metastatic breast cancer. Breast Cancer Res. 2006; 8:R48. https://doi.org/10.1186/ bcr1536. [PubMed]

8. Iwaya K, Tsuda H, Hiraide H, Tamaki K, Tamakuma S, Fukutomi T, Mukai K, Hirohashi S. Nuclear p53 immunoreaction associated with poor prognosis of breast cancer. Jpn J Cancer Res. 1991; 82:835-40. https://doi. org/10.1111/j.1349-7006.1991.tb02710.x. [PubMed]

9. Ostrowski JL, Sawan A, Henry L, Wright C, Henry JA, Hennessy C, Lennard TJ, Angus B, Horne CH. p53 expression in human breast cancer related to survival and prognostic factors: an immunohistochemical study. J Pathol. 1991; 164:75-81. https://doi.org/10.1002/path.1711640113. [PubMed]

10. Rossner P Jr, Gammon MD, Zhang YJ, Terry MB, Hibshoosh H, Memeo L, Mansukhani M, Long CM, Garbowski G, Agrawal M, Kalra TS, Gaudet MM, Teitelbaum SL, et al. Mutations in p53, p53 protein overexpression and breast cancer survival. J Cell Mol Med. 2009; 13:3847-57. https:// doi.org/10.1111/j.1582-4934.2008.00553.x. [PubMed]

11. Olivier M, Langerød A, Carrieri P, Bergh J, Klaar S, Eyfjord J, Theillet C, Rodriguez C, Lidereau R, Bièche I, Varley J, Bignon Y, Uhrhammer N, et al. The clinical value of somatic TP53 gene mutations in 1,794 patients with breast cancer. Clin Cancer Res. 2006; 12:1157-67. https://doi. org/10.1158/1078-0432.CCR-05-1029. [PubMed]

12. Blaszyk H, Hartmann A, Cunningham JM, Schaid D, Wold LE, Kovach JS, Sommer SS. A prospective trial of midwest breast cancer patients: a p53 gene mutation is the most important predictor of adverse outcome. Int J Cancer. 2000; 89:32-38. https://doi. org/10.1002/(sici)1097-0215(20000120)89:1\%3C32::aidijc6\%3E3.0.co;2-g. [PubMed] 
13. Rong G, Yi Z, Ma F, Guan Y, Xu Y, Li L, Xu B. DNA damage response as a prognostic indicator in metastatic breast cancer via mutational analysis. Ann Transl Med. 2021; 9:220. https://doi.org/10.21037/atm-20-2137. [PubMed]

14. Chen MB, Zhu YQ, Xu JY, Wang LQ, Liu CY, Ji ZY, Lu PH. Value of TP53 status for predicting response to neoadjuvant chemotherapy in breast cancer: a meta-analysis. PLoS One. 2012; 7:e39655. https://doi.org/10.1371/journal. pone.0039655. [PubMed]

15. Bertheau P, Lehmann-Che J, Varna M, Dumay A, Poirot B, Porcher R, Turpin E, Plassa LF, de Roquancourt A, Bourstyn E, de Cremoux P, Janin A, Giacchetti S, et al. p53 in breast cancer subtypes and new insights into response to chemotherapy. Breast. 2013 (Suppl 2); 22:S27-29. https:// doi.org/10.1016/i.breast.2013.07.005. [PubMed]

16. Stemke-Hale K, Gonzalez-Angulo AM, Lluch A, Neve RM, Kuo WL, Davies M, Carey M, Hu Z, Guan Y, Sahin A, Symmans WF, Pusztai L, Nolden LK, et al. An integrative genomic and proteomic analysis of PIK3CA, PTEN, and AKT mutations in breast cancer. Cancer Res. 2008; 68:6084-91. https://doi.org/10.1158/0008-5472.CAN-076854. [PubMed]

17. Kotoula V, Karavasilis V, Zagouri F, Kouvatseas G, Giannoulatou E, Gogas H, Lakis S, Pentheroudakis G, Bobos M, Papadopoulou K, Tsolaki E, Pectasides D, Lazaridis G, et al. Effects of TP53 and PIK3CA mutations in early breast cancer: a matter of co-mutation and tumorinfiltrating lymphocytes. Breast Cancer Res Treat. 2016; 158:307-21. https://doi.org/10.1007/s10549-016-3883-Z. [PubMed]
18. Silwal-Pandit L, Vollan HK, Chin SF, Rueda OM, McKinney S, Osako T, Quigley DA, Kristensen VN, Aparicio S, Børresen-Dale AL, Caldas C, Langerød A. TP53 mutation spectrum in breast cancer is subtype specific and has distinct prognostic relevance. Clin Cancer Res. 2014; 20:3569-80. https://doi.org/10.1158/1078-0432.CCR-132943. [PubMed]

19. Ungerleider NA, Rao SG, Shahbandi A, Yee D, Niu T, Frey WD, Jackson JG. Breast cancer survival predicted by TP53 mutation status differs markedly depending on treatment. Breast Cancer Res. 2018; 20:115. https://doi.org/10.1186/ $\underline{\text { s13058-018-1044-5. [PubMed] }}$

20. Robles AI, Harris CC. Clinical outcomes and correlates of TP53 mutations and cancer. Cold Spring Harb Perspect Biol. 2010; 2:a001016. https://doi.org/10.1101/cshperspect. a001016. [PubMed]

21. Richards S, Aziz N, Bale S, Bick D, Das S, Gastier-Foster J, Grody WW, Hegde M, Lyon E, Spector E, Voelkerding K, Rehm HL, and ACMG Laboratory Quality Assurance Committee. Standards and guidelines for the interpretation of sequence variants: a joint consensus recommendation of the American College of Medical Genetics and Genomics and the Association for Molecular Pathology. Genet Med. 2015; 17:405-24. https://doi.org/10.1038/gim.2015.30. [PubMed] 